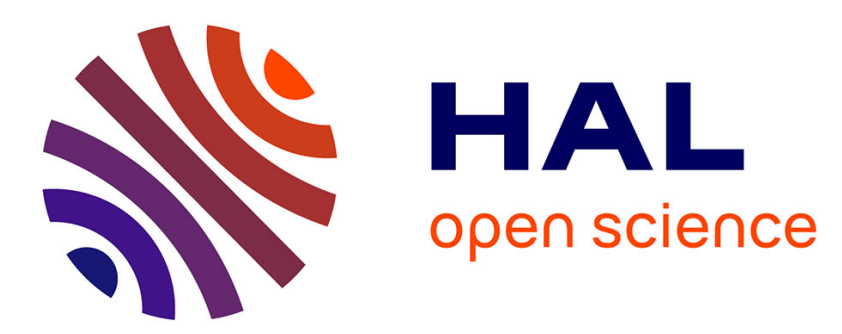

\title{
Minimal Consequences of CMAH and DBA/2J Background on a FKRP Deficient Model
}

Camille Vaubourg, Evelyne Gicquel, Isabelle Richard, William Lostal, Jessica Bellec

\section{- To cite this version:}

Camille Vaubourg, Evelyne Gicquel, Isabelle Richard, William Lostal, Jessica Bellec. Minimal Consequences of CMAH and DBA/2J Background on a FKRP Deficient Model. Journal of Neuromuscular Diseases, 2021, 8 (5), pp.785-793. 10.3233/JND-200487 . hal-03003866v2

\section{HAL Id: hal-03003866 https://hal.science/hal-03003866v2}

Submitted on 29 Nov 2021

HAL is a multi-disciplinary open access archive for the deposit and dissemination of scientific research documents, whether they are published or not. The documents may come from teaching and research institutions in France or abroad, or from public or private research centers.
L'archive ouverte pluridisciplinaire HAL, est destinée au dépôt et à la diffusion de documents scientifiques de niveau recherche, publiés ou non, émanant des établissements d'enseignement et de recherche français ou étrangers, des laboratoires publics ou privés. 


\title{
Minimal Consequences of CMAH and DBA/2 Backgrounds on a FKRP Deficient Model
}

\author{
Camille Vaubourg $^{\mathrm{a}, \mathrm{b}}$, Evelyne Gicquel ${ }^{\mathrm{a}, \mathrm{b}}$, Isabelle Richard ${ }^{\mathrm{a}, \mathrm{b}, *}$, William Lostal ${ }^{\mathrm{a}, \mathrm{b}, 1,2}$ \\ and For Jessica Bellec ${ }^{\mathrm{a}, \mathrm{b}, 2}$ \\ ${ }^{a}$ Généthon, Evry, France \\ ${ }^{\mathrm{b}}$ Université Paris-Saclay, Univ Evry, Inserm, Généthon, Integrare research unit UMR_S951, 91000, Evry, France
}

\begin{abstract}
.
Background: Muscular dystrophies (MD) are a large group of genetic diseases characterized by a progressive loss of muscle. The Latent TGF $\beta$ Binding Protein 4 (LTBP4) in the DBA/2 background and the Cytidine Monophosphate-sialic Acid Hydroxylase (CMAH) proteins were previously identified as genetic modifiers in severe MD.

Objective: We investigated whether these modifiers could also influence a mild phenotype such as the one observed in a mouse model of Limb-Girdle MD2I (LGMD2I).

Methods: The FKRP ${ }^{\mathrm{L} 276 \mathrm{I}}$ mouse model was backcrossed onto the DBA/2 background, and in separate experiments the $\mathrm{Cmah}$ gene was inactivated in $\mathrm{FKRP}^{\mathrm{L} 276 \mathrm{I}}$ mice by crossing with a $\mathrm{Cmah}^{-1-}$ mouse and selecting the double-mutants. The $\mathrm{mdx}$ mouse was used as control for these two genome modifications. Consequences at the histological level as well as quantification of expression level by RT-qPCR of genes relevant for muscular dystrophy were then performed.

Results: We observed minimal to no effect of the DBA/2 background on the mild FKRP ${ }^{\mathrm{L} 276 \mathrm{I}}$ mouse phenotype, while this same background was previously shown to increase inflammation and fibrosis in the $\mathrm{mdx}$ mouse. Similarly, the $\mathrm{Cmah}^{-/-}$ deletion had no observable effect on the FKRP ${ }^{\mathrm{L} 276 \mathrm{I}}$ mouse phenotype whereas it was seen to increase features of regeneration in $m d x$ mice.

Conclusions: These modifiers were not observed to impact the severity of the presentation of the mild FKRP $276 \mathrm{I}$ model. An interesting association of the CMAH modifier with the regeneration process in the $m d x$ model was seen and sheds new light on the influence of this protein on the dystrophic phenotype.
\end{abstract}

Keywords: Muscular dystrophies, genetic background, gene modifiers, animal models

\section{ABBREVIATIONS}

CMAH

cytidine monophosphate-sialic acid hydroxylase

\footnotetext{
${ }^{1}$ Present address: Genosafe, 1 rue de l'Internationale, 91000 Evry, France.

${ }^{2}$ These authors contributed equally to this work.

*Correspondence to: Isabelle Richard, orcid.org/0000-00026505-446X Généthon, 1, bis rue de l'internationale, 91000 Evry, France. Tel.: +33 1694729 38; E-mail: richard@ genethon.fr.
}

$\begin{array}{ll}\text { DMD } & \begin{array}{l}\text { Duchenne muscular dystrophy } \\ \text { diaphragm } \\ \text { Dia }\end{array} \\ \text { ECM } & \begin{array}{l}\text { extracellular matrix } \\ \text { fold-change }\end{array} \\ \text { FC } & \text { fukutin-related protein } \\ \text { FKRP } & \text { fibronectin 1 } \\ \text { FN1 } & \text { growth hormone } \\ \text { GH } & \text { growth hormone receptor } \\ \text { GHR } & \text { hematoxylin-phloxine-saffron } \\ \text { HPS } & \text { limb-girdle muscular dystrophy }\end{array}$




$\begin{array}{ll}\text { LTBP4 } & \begin{array}{l}\text { latent TGF } \beta \text { binding protein } 4 \\ \text { MD }\end{array} \\ \text { muscular dystrophies } \\ \text { MDC1C } & \begin{array}{l}\text { congenital muscular dystrophy } \\ \text { muscle eye brain }\end{array} \\ \text { MEB } & \begin{array}{l}\text { Ministère de l'Enseignement supérieur, } \\ \text { de la Recherche et } \\ \text { de l'Innovation }\end{array} \\ & \text { micro-RNA } \\ \text { miR } & \text { psoas } \\ \text { Pso } & \text { quadriceps } \\ \text { Qua } & \text { standard error of the mean } \\ \text { SEM } & \text { tibialis anterior } \\ \text { TA } & \text { transforming growth factor } \beta \\ \text { TGF } \beta & \text { wild type } \\ \text { WT } & \text { Walker Warburg syndrome } \\ \text { WWS } & \end{array}$

\section{INTRODUCTION}

Muscular dystrophies (MD) are a large group of genetic diseases due to mutations affecting muscle functions. The most frequent forms of the disease include the relatively frequent Duchenne muscular dystrophy (DMD) and the genetically heterogeneous group of limb-girdle muscular dystrophies (LGMD). In these pathologies, the primary genetic default causes a myofiber degeneration that triggers a regenerative and inflammatory response. With the evolution of the disease, a replacement of myofibers by fibrotic and/or fat tissue occurs, leading to progressive muscle weakness [1]. The severity of the clinical presentation is variable between the different MD, but also between patients affected by the same form according to factors such as the type of mutations or additional genetic modifiers. In particular, transcriptome and genome profiling led to the identification of variants in SPP1, ANXA6, CD40 or Growth Hormone and its receptor (GH/GHR) as modifiers which can alter strength and ambulation in patients affected by DMD [2-4]. An interesting genetic study performed on $\gamma$-sarcoglycan null mice, a model of Limb-Girdle Muscular Dystrophy 2C (LGMD2C), identified a polymorphism of Latent TGF $\beta$ Binding Protein 4 (LTBP4), specific of the DBA/2 background, which leads to an exacerbated phenotype [5]. This observation led to the demonstration that single nucleotide polymorphisms in the LTBP4 gene were associated with an earlier loss of ambulation in DMD patients [3]. The implication of LTBP4 was also confirmed to worsen the phenotype of the $m d x$ mouse, a mouse model carrying a stop mutation in the DMD gene, when backcrossed on the DBA/2 background [6-8]. In another study, the comparison of activated/inactivated genes present in Human and mouse led to the identification of the cytidine monophosphate-sialic acid hydroxylase $(\mathrm{CMAH})$ as a potential modifier of DMD. During evolution, this gene has been inactivated in Human, but not in mouse. It was hypothesized that this genetic loss could explain why the consequences of dystrophin mutation are more severe in Human than in the mouse species. Consequently, the $m d x$ mutation was evaluated on a $\mathrm{Cmah}^{-/-}$ background, resulting in a modified glycome and muscle alteration closer to the human clinical presentation [9].

The dystrophic process was previously described to be modulated by disrupting the Cmah gene or by introducing dystrophy mutations into the DBA/2 background. In this study, we sought to investigate whether these backgrounds could also worsen a milder phenotype such as the one observed in a mouse model of LGMD2I (LGMD-R9 according to the new nomenclature [10]). LGMD2I is the less severe presentation associated with defects in Fukutin-related protein (FKRP) which can also lead to more severe pathologies like Walker Warburg Syndrome (WWS), Muscle Eye Brain (MEB) disease or Congenital Muscular Dystrophy (MDC1C) [11, 12]. Comparison of the dystrophic presentation in different mouse models for LGMD2I [13-17] showed that the nature of the mutation and FKRP expression level were critical for the phenotype severity [14]. However, no study has been performed to describe the effect of genetic backgrounds in any of these models. Therefore, we investigated, in a side by side study, the consequences of the reduced activity of LTBP4 [18] and of the inactivation of CMAH on dystrophic features using a knock-in model of LGMD type 2I [FKRP ${ }^{\mathrm{L} 276 \mathrm{I}}$ ] [16], together with the severe $m d x$ model previously investigated. The FKRP ${ }^{\mathrm{L} 276 \mathrm{I}}$ model carries a L276I missense mutation which corresponds to the most frequent mutation observed in patients [16]. The evaluation of the models after backcrossing onto the DBA/2 and $\mathrm{Cmah}^{-/-}$backgrounds led to the observation that the DBA/2 background has no observable effect on FKRP ${ }^{\mathrm{L} 276 \mathrm{I}}$ mouse phenotype, although some changes are present at molecular level. The $\mathrm{Cmah}^{-/-}$background has virtually no effect on the FKRP ${ }^{\mathrm{L} 276 \mathrm{I}}$ mouse and an effect on the regeneration level in the $m d x$ mice. Altogether, CMAH and LTBP4 deficiency did not further worsen the FKRP 
phenotype in the limb and respiratory muscles, and adding these alleles did not provide more relevant animal model for the pathophysiological characterisation of FKRP deficiency.

\section{MATERIALS AND METHODS}

\section{Animals}

$M d x \quad$ (C57BL/10ScSn-Dmdmdx/J), DBA/2$m d x$ (D2.B10-Dmdmdx/J), C57BL/6, C57BL/10, $\mathrm{DBA} / 2, \quad \mathrm{Cmah}^{-1-} \quad\left(\mathrm{B} 6.129 \mathrm{X} 1-\mathrm{Cmah}^{\text {tm1Avrk }} / \mathrm{J}\right)$ and $\mathrm{Cmah}^{-1-}-m d x \quad$ (B10.Cg-Cmah ${ }^{\text {tm } 1 \text { Avrk }}$ $\left.D m d^{m d x} / \mathrm{PtmJ}\right)$ mice were supplied by the Jackson Laboratory. FKRP ${ }^{\mathrm{L} 276 \mathrm{I}}$ mice were generated and previously characterized [16]. DBA/2-FKRP ${ }^{\mathrm{L} 276 \mathrm{I}}$ mice were obtained in our animal facility by crossing FKRP $^{\mathrm{L} 276 \mathrm{I}}$ with $\mathrm{DBA} / 2$ for 10 generations, while $\mathrm{Cmah}^{-/-}$-FKRP ${ }^{\mathrm{L} 276 \mathrm{I}}$ were generated from crossing with $\mathrm{Cmah}^{-/-}$mice, followed by selection of double homozygous mutants. The selection of mutants for both Fkrp and Cmah genes was achieved by genotyping using already described protocols and PCR primers $[16,19]$.

Dystrophin-deficient mice and their wild-type (WT) counterparts were sacrificed at 10 weeks. FKRP-deficient mice and their WT counterparts were sacrificed at 24 weeks. Four animals per group were used for the study.

All mice were handled according to the European guidelines for the human care and use of experimental animals, and all procedures on animals were approved by the local ethics committee and the regulatory affairs of the French Ministry of Research (MESRI) under the number APAFIS\#3519. Animals were housed in a barrier facility with $12 \mathrm{~h}$ light $/ 12 \mathrm{~h}$ dark cycles, and provided food and water ad libitum. In this study, only male mice were used.

\section{Muscle staining}

Muscles (psoas, tibialis anterior, quadriceps and diaphragm) were sampled and frozen in isopentane cooled in liquid nitrogen. Transverse cryosections (8$10 \mu \mathrm{m})$ were prepared from frozen muscles and were processed for hematoxylin-phloxine-saffron (HPS) histological staining.

\section{$R N A$ extraction and quantitative $R T-P C R$}

Total RNA was extracted from frozen muscles using Trizol (Thermo Fisher Scientific, Waltham,
MA, USA), according to the manufacturer protocol. Total RNA was quantified using a Nanodrop 8000 spectrophotometer (Labtech, Wilmington Delaware).

To measure gene expression, $1 \mu \mathrm{g}$ of total RNA was reverse-transcribed using a mixture of random hexamer oligonucleotides, oligo-dT and RevertAid H Minus First Strand cDNA Synthesis Kit (Thermo Fisher Scientific). Real-time PCR was performed using LightCycler 480 system (Roche, Bâle, Switzerland) with the following Taqman Gene Expression assays (Thermo Fisher Scientific): Fibronectin1 (Fn1, Mm01256744_m1), Cd11b (Mm00434455_m1), Mymk (Mm00481256_m1) according to the manufacturer protocol. Results obtained with the ubiquitous acidic ribosomal phosphoprotein gene $(P O)$ were used to normalize the data across samples. The primers and Taqman probe used for $P O$ amplification were: P0.F (5'-CTCCAAGCAGATGCAGCAGA-3'), P0.R $\left(5^{\prime}\right.$-ACCATGATGCGCAAGGCCAT- $\left.3^{\prime}\right)$ and P0.P (5'-CCGTGGTGCTGATGGGCAAGAA-3'). Each experiment was performed in duplicate.

To measure micro-RNA (miR) expression, $800 \mathrm{ng}$ of total RNA were reverse-transcribed using Taqman MicroRNA assays and Taqman MicroRNA Reverse Transcription Kit (Thermo Fisher Scientific). Realtime PCR was performed using LightCycler 480 system (Roche, Bâle, Switzerland), with the following Taqman MicroRNA assays (Thermo Fisher Scientific): miR-21 (hsa-miR-21-5p), miR-142.3p (hsa-miR142-3p), miR-31 (mmu-miR-31), U6 small nuclear RNA (001973). Results obtained with the U6 small nuclear RNA were used to normalize data across samples. Each experiment was performed in duplicate.

\section{Data and statistical analyses}

Quantitative PCR raw data were extracted from LightCycler480 software (Roche). Data were analyzed using the DDCt method [20] and expressed as Fold-Change (FC) compared to WT. Data for each group are represented as the mean plus standard error of the mean (SEM). Animal groups of the DBA/2 and $\mathrm{Cmah}^{-1-}$ backgrounds were compared to the parental deficient C57BL/6 or C57BL/10 counterpart by one-way ANOVA using Prism 7 software, GraphPad. Statistical significance is represented by stars: (*) for $P<0.05,(* *)$ for $P<0.01$ and $(* * *)$ for $P<0.001$. 


\section{RESULTS}

The FKRP ${ }^{\text {276I }}$ mouse, a model for LGMD2I, was modified in two ways: either by backcrossing onto the DBA/2 mouse strain, or by crossing with the $\mathrm{Cmah}^{-/-}$strain and selecting individuals carrying both mutations. The strains B10.CgCmah $^{\text {tm } 1 \text { Avrk }} \mathrm{Dmd}^{m d x} / \mathrm{PtmJ}\left(\mathrm{Cmah}^{-/-}-m d x\right)$ and D2.B10-Dmdmdx/J (DBA/2- $m d x$ ), two models carrying the $m d x$ mutation and for which the effect of these two modifiers has already been reported [69], were used in parallel. The double-homozygous animals were then evaluated at an age at which dystrophic signs are well established for the parental dystrophic models and using muscles evaluated in previous studies $[16,21]$. It is worth pointing out that neither DBA/2 nor $\mathrm{Cmah}^{-/-}$mice presented dystrophic signs at the corresponding ages (Figure S1).

The FKRP ${ }^{\mathrm{L} 276 \mathrm{I}}$ mouse model is a mildly affected model. Therefore, we evaluated the consequences of the backcrossing on DBA/2-FKRP ${ }^{\mathrm{L} 276 \mathrm{I}}$ and $\mathrm{Cmah}^{-1-}$-FKRP ${ }^{\mathrm{L} 276 \mathrm{I}}$ at 6 months of age. At this age, the parental mouse model is described to present a mild dystrophic phenotype, with centronucleation observed only in proximal muscles as psoas and gluteus [16] but not in distal muscles as tibialis anterior. In line with this description, centronucleated fibers were observed in psoas but not in tibialis anterior. In addition, small areas of fibrosis and adipocytes were observed in diaphragm (Fig. 1A). No aggravation sign was noticeable in neither of the two crossings in these three muscles (Fig. 1A). According to the disease evolution, the DBA/2- $m d x$ and $\mathrm{Cmah}^{-1-}-m d x$ models were observed earlier than the FKRP ${ }^{\mathrm{L} 276 \mathrm{I}}$ models, at the age of 2.5 months. At this age, the $m d x$ mouse presents an important level of centronucleated fibers (nearly $100 \%$ of the fibers) but the phenotype has not yet evolved towards fibrosis and adipogenesis. Histological stainings of different muscles from DBA/2-mdx mice (tibialis anterior, quadriceps and diaphragm), highlighted large areas of degeneration overspread by fibrosis and inflammatory cells and even calcification (Fig. 1B). For $\mathrm{Cmah}^{-/-}-m d x$ mice, no change was observed at the histological level at that age (Fig. 1A).

In order to quantitatively compare the dystrophic impairment depending on the genetic backgrounds, we measured the expression of genes selected as markers of the different features of the dystrophic process, namely degeneration/regeneration, inflam- mation and fibrosis. For each of these characteristics, both a coding gene and a non-coding gene were quantified (Fig. 2 and Table S1 for individual data).

Regeneration was first assessed, using the quantification of the Mymk gene, coding for myomaker, a factor involved in myoblast fusion [22], and the micro-RNA miR-31, expressed in proliferating myoblasts [23]. In the FKRP ${ }^{\mathrm{L} 276 \mathrm{I}}$ mouse models, an increase was observed for the DBA/2 background, which was not observed at the histological level, reaching significance for Mymk in psoas and tibialis anterior (respectively 4.8-fold increase and 6.9-fold increase) and for miR-31 in tibialis anterior (5-fold increase) whereas there was no difference in the expression of the markers for the $\mathrm{Cmah}^{-/-}$strain. In the $m d x$ models, the expression of both genes was elevated compared to WT counterparts, which is in accordance with the high level of regeneration in all three genetic backgrounds, as shown above by the important number of centronucleated fibers. The crossing with the DBA/2 background did not induce an overall change in the regenerative markers. In contrast, the crossing with the $\mathrm{Cmah}^{-/-}$strain seemed to increase regeneration, since $M y m k$ and miR-31 were found significantly elevated in most muscles with this background, compared to the parental $m d x$ model. The increase can be observed in quadriceps (1.9fold increase) and in diaphragm (3.7-fold increase) for Mymk, and in quadriceps (3.8-fold increase) and in tibialis anterior (9.5-fold increase) for miR-31 (Fig. 2).

The effect of the backcrossing on inflammation was evaluated using the quantification of gene expression of $C d 11 b$, a macrophage marker, and miR-142.3p, which is expressed in all cells of hematopoietic origin [24]. For both FKRP ${ }^{\mathrm{L} 276 \mathrm{I}}$ and $m d x$ models, the crossing with $\mathrm{DBA} / 2$ background induced an increase of both $C d 11 b$ and miR-142.3p expression, which was more pronounced in the DBA/2- $m d x$ strain. This was correlated with the presence of inflammatory cells positive for CD11b staining in the corresponding sections (data not shown). In FKRP ${ }^{\text {L276I }}$ model, the increase was only observed in tibialis anterior (3.0-fold increase for $C d 11 \mathrm{~b}$ and 4.5-fold increase for miR-142.3p) (Fig. 2 ). In the $m d x$ model, there was a general increase of the markers in all muscles (from 2.5 to 9-fold increase for $C d 11 \mathrm{~b}$ and 4.2 to 12.0 -fold increase for miR142.3p). The $\mathrm{Cmah}^{-/-}$background had no impact on the expression level of these two genes in any of the models. 


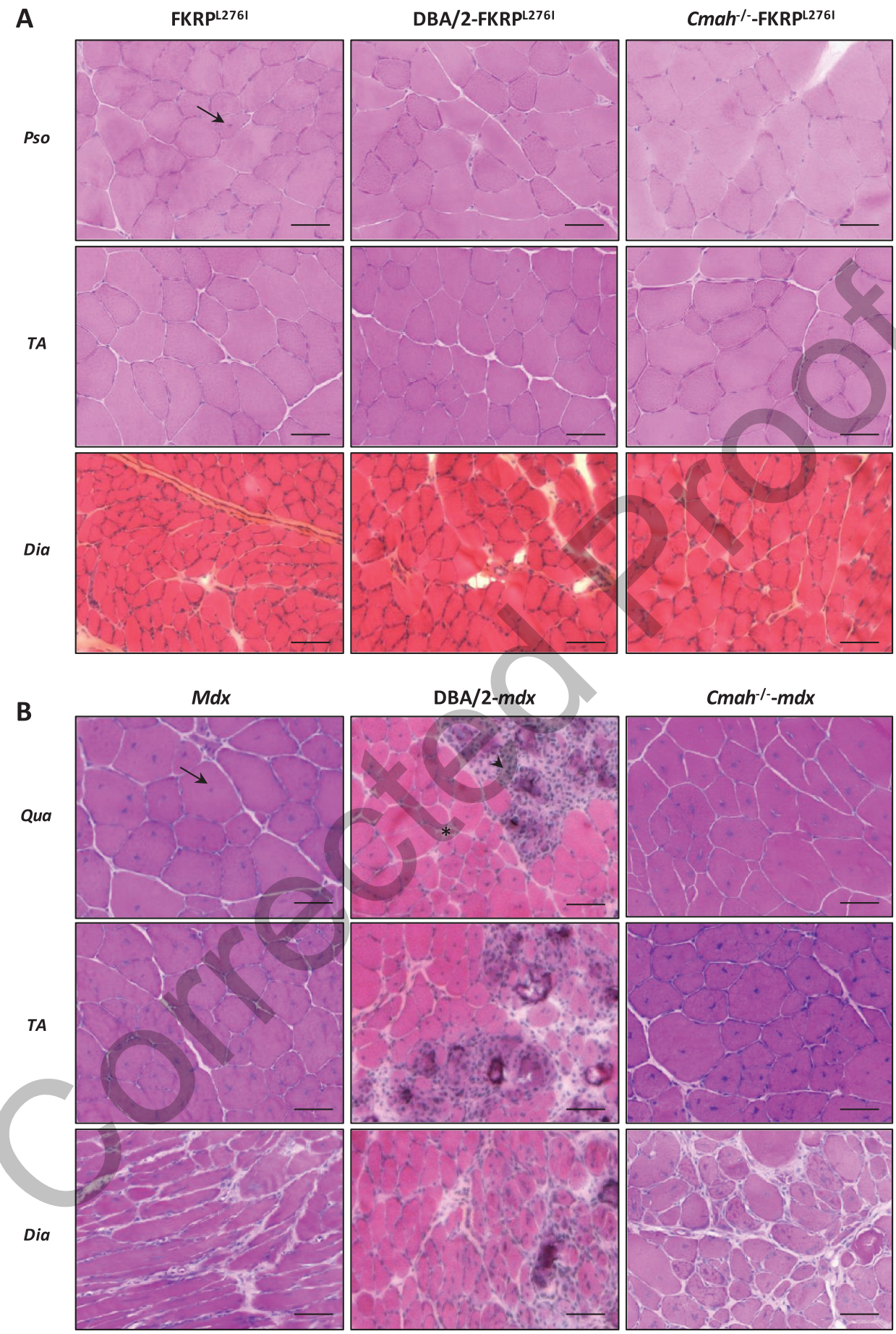

Fig. 1. Histological characterization of FKRP and dystrophin deficient mouse models. A. Hematoxylin-phloxine-saffron stained muscle sections of psoas (Pso), tibialis anterior (TA) and diaphragm (Dia) of FKRP-deficient models. B. Hematoxylin-phloxine-saffron stained muscle sections of quadriceps (Qua), tibialis anterior (TA) and diaphragm (Dia) of dystrophin-deficient models. As an example, centronucleated fibers, fibrosis and inflammation are indicated respectively by arrow, asterisk and head arrow. Size bars: $50 \mu \mathrm{m}$. 

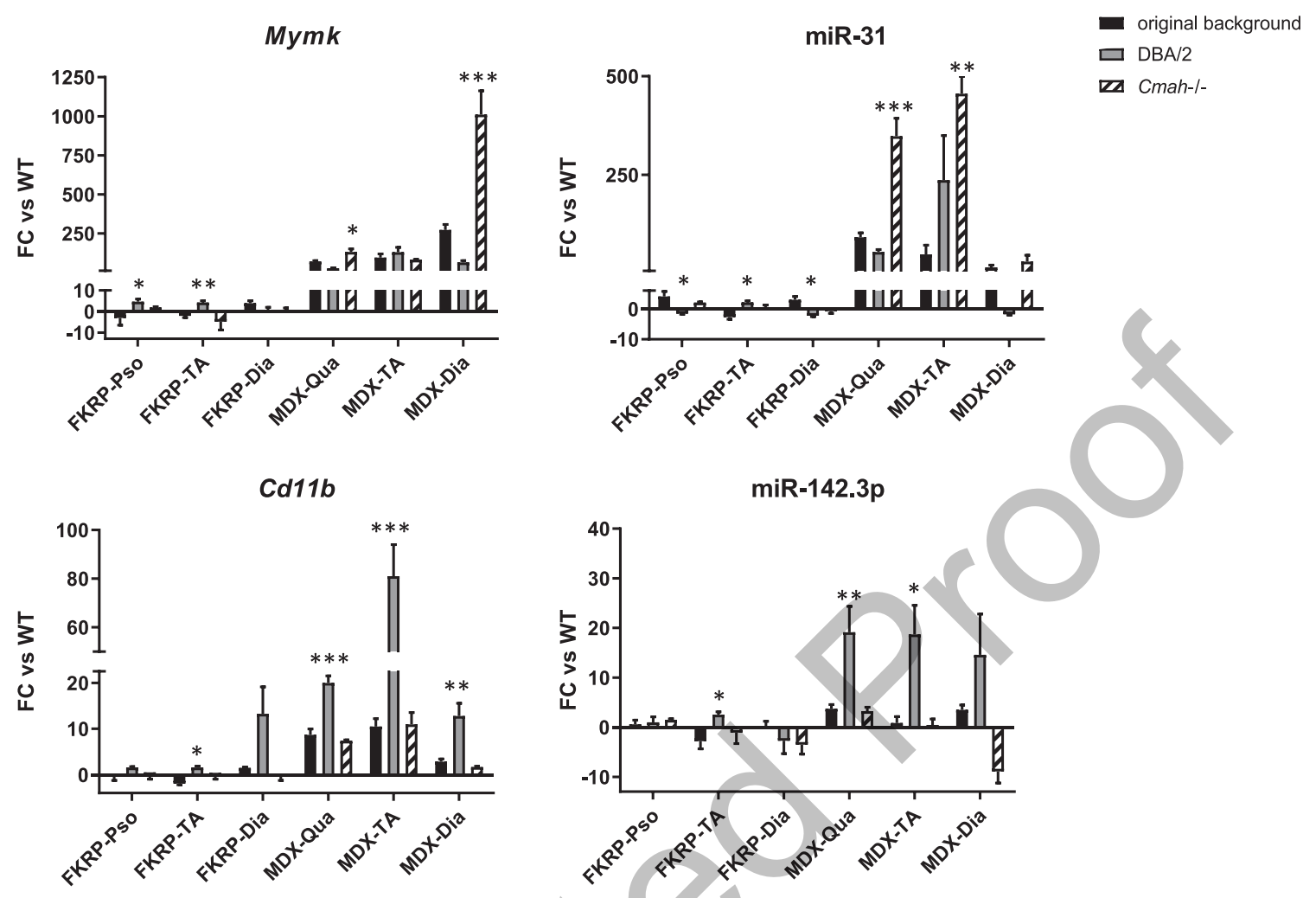

$\operatorname{miR}-142.3 p$

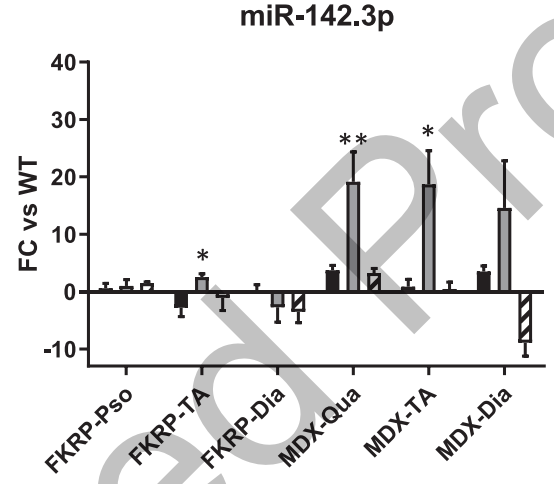

Fn1

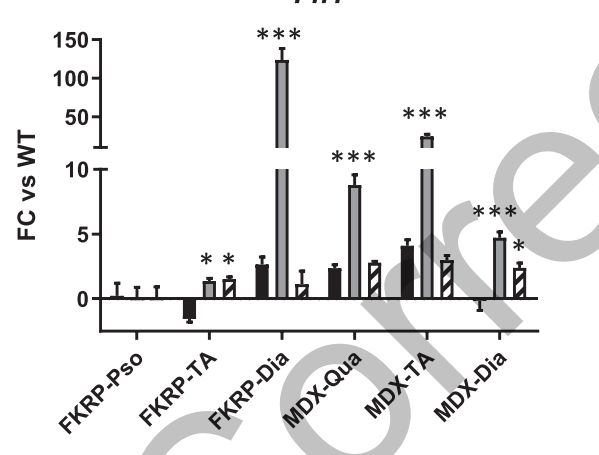

miR-21

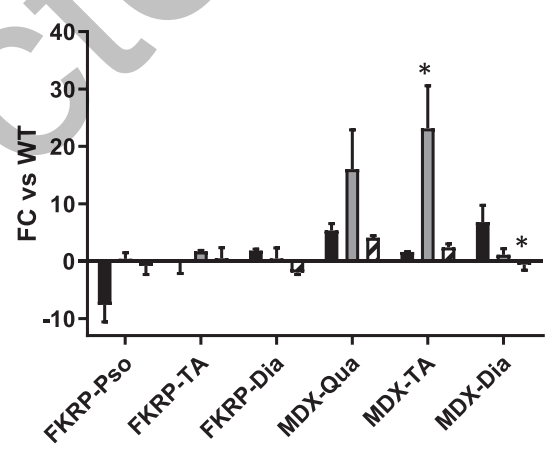

Fig. 2. Quantitative evaluation of dystrophic impairment in deficient mouse models. Levels of expression of regeneration, inflammation and fibrosis-related genes in the FKRP and dystrophin deficient mouse models were measured by RT-qPCR. Data were normalized with data from wild-type (C57BL/6 or C57BL/10, DBA/2, $\mathrm{Cmah}^{-/-}$) samples. Statistical analyses were performed versus FKRP ${ }^{\mathrm{L} 276 \mathrm{I}}$ (FKRP-deficient model) or $m d x$ (dystrophin-deficient model). (*) for $P<0.05,(* *)$ for $P<0.01$ and (***) for $P<0.001$.

The levels of expression of fibronectin 1 (FN1), a component of the extracellular matrix [25], and of miR-21, a positive regulator of TGF $\beta$ pathway [26], were used for fibrosis assessment. In FKRP ${ }^{L 276 I}$ mice, the switch to any of the two backgrounds had a similar effect with an increased expression of $F n l$ in the tibialis anterior (1.4 and 2.2-fold increase with DBA/2 and $\mathrm{Cmah}^{-1-}$ backgrounds, respectively) and no significant difference for miR-21 expression.
Surprisingly, an important increase of the level of $F n I$ was observed in the diaphragm for the DBA/2 background (123-fold increase). For DBA/2- $m d x$ mice, $F n 1$ expression was increased in all the observed muscles (3.7 to 5.9-fold increase), which was correlated with an increase of miR-21 expression in quadriceps and in tibialis anterior (respectively 3.0 and 14.6fold increase), but not in diaphragm where it was decreased. The $\mathrm{Cmah}^{-/-}$background had no effect 
on the expression of the two marker genes in all muscles but the diaphragm where miR-21 was decreased (Fig. 2). Thus, the DBA/2 background seems to have a more important effect on fibrosis than the $\mathrm{Cmah}^{-/-}$ background in a severe model as $m d x$ mouse and in diaphragm tissue of the mildly affected FKRP ${ }^{\mathrm{L} 276 \mathrm{I}}$ model.

\section{DISCUSSION}

In this study, we investigated the hypothesis that known modifiers of the presentation of dystrophin deficiency could also worsen a milder phenotype such as the FKRP ${ }^{\mathrm{L} 276 \mathrm{I}}$ model by crossing this model with two mouse strains harbouring mutations in modifier genes described to exacerbate MD. In addition to the histological assessment, our analysis of the influence of the genetic modifiers was defined molecularly using quantification of expression of specific genes. Thanks to this analysis, we were able to detect precocious dystrophic features by quantitative PCR that were not visible by histological observation. We also observed that the dystrophic process present in the diaphragm is different from the pattern observed in limb muscles and therefore may call for specific makers for this muscle.

Overall, we showed that the DBA/2 background has a weak effect on FKRP ${ }^{\mathrm{L} 276 \mathrm{I}}$ mouse phenotype and the Cmah knock-out has none. It is noteworthy that the DBA/2 background induces an important increase of the expression level of $F n l$, a component of the extracellular matrix. although no fibrosis deposit was observed at the histological level. In addition, we observed that the worsening of the phenotype observed in the severe $m d x$ mouse model on the DBA/2 or $\mathrm{Cmah}^{-1-}$ backgrounds originates from different modulated pathways. The DBA/2 background is associated with an elevated inflammation and fibrotic tissue replacement, while the $\mathrm{Cmah}^{-/-}$ background leads to an increase of the regeneration process in most of the $m d x$ muscles compared to the C57BL/10 background. This interesting association with the regeneration process sheds a new light on the influence of this background on the dystrophic phenotype.

The DBA/2 genetic background is characterized by a partial loss-of-function of LTBP4 [18], a protein participating in the control of the TGF $\beta$ signalling. TGF $\beta 1$, acting via the Smad2/3/4 pathway, induces the expression of genes coding for extracellular matrix (ECM) components and enzymes inhibiting
ECM degradation [27]. This pathway is crucial for muscle repair in case of tissue damages but its overactivation leads to an excessive ECM deposition and fibrosis. TGF $\beta$ also stimulates the inflammatory response by acting as a potent chemoattractant for immune cells [28]. The consequences of the impaired function of DBA/2 LTBP4 mutation corresponds more to a lack of control of the TGF $\beta$ signaling rather than a hyperactivity per se. This context is thus consistent with the observed consequences: a worsening in an inflammatory context in the $m d x$ animals, an absence of consequence in WT and a minimal effect in skeletal muscles of FKRP-deficient model. In the diaphragm of DBA/2-FKRP ${ }^{\mathrm{L} 276 \mathrm{I}}$ mice, the increase of the $F n l$ expression and the absence of large fibrosis areas at the histological level could indicate that a compensatory mechanism counterbalances this increase of expression and inhibit fibrosis deposit. Fnl gene is thereby not the best marker to assess fibrosis in the diaphragm. Of note, the $m d x$ muscles in the DBA/2 background present an important level of calcification which is also in line with the role of TGF $\beta$ in heterotopic ossification $[29,30]$.

Interestingly and in contrast to the DBA/2 background, the biomarker analysis pinpointed that $\mathrm{Cmah}$ deficiency has an aggravating effect mainly on the regeneration process in $m d x$ mice only. CMAH is the only enzyme known to synthesize Neu5Gc from Neu5Ac, both being the major kind of sialic acids present at the surface of all mammalian cells, including myofibers and satellite cells [31]. Sialic acids play a role in cell-cell and cell-ECM interactions, notably in the adhesion of cells to ECM and in cell migration $[32,33]$. The mechanism by which the modification of sialylation at the membrane may influence regeneration is not known. However, it can be hypothesized that some phenomena such as quiescence of the satellite cells or fusion of these cells to the fibers could be impacted by the sialylation of the involved molecules. One can cite as examples of such candidate molecules the calcitonin receptor for the quiescence in the niche $[34,35]$ or Neural Cell Adhesion Molecule (NCAM) for the fusion $[36,37]$. Interestingly, it was observed that, in the absence of Neu5Gc, the binding of $\alpha$ dystroglycan to its ECM ligands laminin and agrin was decreased, and this was proposed as a mechanism contributing to the more severe phenotype observed with Cmah inactivation [9]. Since, in FKRP-deficient models, the binding of $\alpha$-dystroglycan with its ECM partners is already compromised, the lack of worsening of the phenotype would be consistent with this 
mechanism [9]. This point of the study would call for further investigations.

In conclusion, we showed an interesting association of the CMAH modifier with the regeneration process in the $m d x$ model, shedding a new light on the influence of this protein on the dystrophic phenotype. We also showed that none of the two modifiers impacted the severity of the presentation in the FKRP $^{\mathrm{L} 276 \mathrm{I}}$ model. A potential limitation of our study relates to the low number of animals used, i.e. 4 mice per group. Nevertheless, while increasing the number of animals could have allowed detection of more subtle differences at the level of the biomarker analysis, the inter-individual homogeneity observed at the level of muscle histology supports the claims of lack of consequences of the changes of background for FKRP deficiency. Another limitation is the absence of functional tests to evaluate the difference between animals in term of muscle force. Since usually the force is tightly correlated with the histological aspects in muscular dystrophies, it is likely that such analysis would have led to the same conclusion. Finally, it can be postulated that the absence of impact on the severity of the presentation in the FKRP ${ }^{\mathrm{L} 276 \mathrm{I}}$ model is possibly due to the mechanism of action of the modifiers. The choice of the genetic background to worsen a phenotype or to evaluate a specific treatment should be selected according to the features of interest and according to the modifier genes involved.

\section{ACKNOWLEDGMENTS}

We are grateful to Histology team of Généthon for technical support. This work was supported by the Leducq Fundation (Grant number: 13CVD04).

\section{CONFLICT OF INTEREST}

The authors have no conflict of interest to report.

\section{SUPPLEMENTARY MATERIAL}

Figure S1: Histological characterization of wildtype mice showing that neither DBA/2 nor $\mathrm{Cmah}^{-/-}$ mice presented dystrophic signs at the evaluated ages. Table S1: Fold changes of miR-31, miR-142.3p, miR21, Mymk, Fnl and $C d 11 b$ gene expression relative to wild-type animal calculated for each biological replicate.

\section{REFERENCES}

[1] Wallace GQ, McNally EM. Mechanisms of muscle degeneration, regeneration, and repair in the muscular dystrophies. Annu Rev Physiol. 2009;71:37-57; doi: 10.1146/annurev.physiol.010908.163216

[2] Quattrocelli M, Capote J, Ohiri JC, Warner JL, Vo AH, Earley JU, et al. Genetic modifiers of muscular dystrophy act on sarcolemmal resealing and recovery from injury. PLoS Genet. 2017;13(10):e1007070; doi: 10.1371/journal.pgen. 1007070

[3] Vo AH, McNally EM. Modifier genes and their effect on Duchenne muscular dystrophy. Curr Opin Neurol. 2015;28(5):528-34; doi: 10.1097/WCO.0000000000000240

[4] Hightower RM, Alexander MS. Genetic modifiers of Duchenne and facioscapulohumeral muscular dystrophies. Muscle Nerve. 2018;57(1):6-15; doi: 10.1002/mus.25953.

[5] Heydemann A, Huber JM, Demonbreun A, Hadhazy M, McNally EM. Genetic background influences muscular dystrophy. Neuromuscul Disord. 2005;15(9-10):601-9; doi: 10.1016/j.nmd.2005.05.004

[6] Fukada S, Morikawa D, Yamamoto Y, Yoshida T, Sumie $\mathrm{N}$, Yamaguchi M, et al. Genetic background affects properties of satellite cells and mdx phenotypes. Am J Pathol. 2010;176(5):2414-24; doi: 10.2353/ajpath.2010.090887

[7] Coley WD, Bogdanik L, Vila MC, Yu Q, Van Der Meulen $\mathrm{JH}$, Rayavarapu S, et al. Effect of genetic background on the dystrophic phenotype in mdx mice. Hum Mol Genet. 2016;25(1):130-45; doi: 10.1093/hmg/ddv460

[8] Rodrigues M, Echigoya Y, Maruyama R, Lim KR, Fukada SI, Yokota T. Impaired regenerative capacity and lower revertant fibre expansion in dystrophin-deficient mdx muscles on DBA/2 background. Sci Rep. 2016;6:38371; doi: $10.1038 /$ srep38371

[9] Chandrasekharan K, Yoon JH, Xu Y, deVries S, Camboni $\mathrm{M}$, Janssen PM, et al. A human-specific deletion in mouse Cmah increases disease severity in the $\mathrm{mdx}$ model of Duchenne muscular dystrophy. Sci Transl Med. 2010;2(42):42ra54; doi: 10.1126/scitranslmed.3000692

[10] Straub V, Murphy A, Udd B, group Lws. 229th ENMC international workshop: Limb girdle muscular dystrophies - Nomenclature and reformed classification Naarden, the Netherlands, 17-19 March 2017. Neuromuscul Disord. 2018;28(8):702-10; doi: 10.1016/j.nmd.2018.05.007

[11] Bourteel H, Vermersch P, Cuisset JM, Maurage CA, Laforet $\mathrm{P}$, Richard P, et al. Clinical and mutational spectrum of limbgirdle muscular dystrophy type $2 \mathrm{I}$ in 11 French patients. J Neurol Neurosurg Psychiatry. 2009;80(12):1405-8; doi: 10.1136/jnnp.2007.141804

[12] Brockington M, Blake DJ, Prandini P, Brown SC, Torelli $\mathrm{S}$, Benson MA, et al. Mutations in the fukutin-related protein gene (FKRP) cause a form of congenital muscular dystrophy with secondary laminin alpha2 deficiency and abnormal glycosylation of alpha-dystroglycan. Am J Hum Genet. 2001;69(6):1198-209; doi: 10.1086/324412

[13] Ackroyd MR, Skordis L, Kaluarachchi M, Godwin J, Prior S, Fidanboylu M, et al. Reduced expression of fukutin related protein in mice results in a model for fukutin related protein associated muscular dystrophies. Brain. 2009;132(Pt 2):439-51; doi: 10.1093/brain/awn335

[14] Blaeser A, Keramaris E, Chan YM, Sparks S, Cowley D, Xiao X, et al. Mouse models of fukutin-related protein mutations show a wide range of disease phenotypes. Hum Genet. 2013;132(8):923-34; doi: 10.1007/s00439-013-1302-7 
[15] Chan YM, Keramaris-Vrantsis E, Lidov HG, Norton JH, Zinchenko N, Gruber HE, et al. Fukutin-related protein is essential for mouse muscle, brain and eye development and mutation recapitulates the wide clinical spectrums of dystroglycanopathies. Hum Mol Genet. 2010;19(20):3995-4006; doi: $10.1093 / \mathrm{hmg} / \mathrm{ddq} 314$

[16] Gicquel E, Maizonnier N, Foltz SJ, Martin WJ, Bourg $\mathrm{N}$, Svinartchouk $\mathrm{F}$, et al. AAV-mediated transfer of FKRP shows therapeutic efficacy in a murine model but requires control of gene expression. Hum Mol Genet. 2017;26(10):1952-65; doi: 10.1093/hmg/ddx066

[17] Krag TO, Vissing J. A New Mouse Model of Limb-Girdle Muscular Dystrophy Type 2I Homozygous for the Common L276I Mutation Mimicking the Mild Phenotype in Humans. J Neuropathol Exp Neurol. 2015;74(12):1137-46; doi: 10.1097/NEN.0000000000000260

[18] Ceco E, Bogdanovich S, Gardner B, Miller T, DeJesus A, Earley JU, et al. Targeting latent TGFbeta release in muscular dystrophy. Sci Transl Med. 2014;6(259):259ra144; doi: 10.1126/scitranslmed.3010018

[19] Hedlund M, Tangvoranuntakul P, Takematsu H, Long JM, Housley GD, Kozutsumi Y, et al. N-glycolylneuraminic acid deficiency in mice: implications for human biology and evolution. Mol Cell Biol. 2007;27(12):4340-6; doi: 10.1128/MCB.00379-07

[20] Livak KJ, Schmittgen TD. Analysis of relative gene expression data using real-time quantitative PCR and the 2(-Delta Delta C(T)) Method. Methods. 2001;25(4):402-8; doi: 10.1006/meth.2001.1262

[21] Bulfield G, Siller WG, Wight PA, Moore KJ. X chromosome-linked muscular dystrophy $(\mathrm{mdx})$ in the mouse. Proc Natl Acad Sci U S A. 1984;81(4):1189-92; doi: 10.1073/pnas.81.4.1189

[22] Millay DP, Sutherland LB, Bassel-Duby R, Olson EN. Myomaker is essential for muscle regeneration. Genes Dev. 2014;28(15):1641-6; doi: 10.1101/gad.247205.114

[23] Cacchiarelli D, Incitti T, Martone J, Cesana M, Cazzella $\mathrm{V}$, Santini T, et al. miR-31 modulates dystrophin expression: new implications for Duchenne muscular dystrophy therapy. EMBO Rep. 2011;12(2):136-41; doi: 10.1038/embor.2010.208

[24] Chen CZ, Li L, Lodish HF, Bartel DP. MicroRNAs modulate hematopoietic lineage differentiation. Science. 2004;303(5654):83-6; doi: 10.1126/science. 1091903

[25] Ohlendieck K, Swandulla D. [Molecular pathogenesis of Duchenne muscular dystrophy-related fibrosis]. Pathologe. 2017;38(1):21-9; doi: 10.1007/s00292-017-0265-1

[26] O'Reilly S, Ciechomska M, Fullard N, Przyborski S, van Laar JM. IL-13 mediates collagen deposition via STAT6 and microRNA-135b: a role for epigenetics. Sci Rep. 2016;6:25066; doi: 10.1038/srep25066
[27] Mann CJ, Perdiguero E, Kharraz Y, Aguilar S, Pessina P, Serrano AL, et al. Aberrant repair and fibrosis development in skeletal muscle. Skelet Muscle. 2011;1(1):21; doi: 10.1186/2044-5040-1-21

[28] Kim J, Lee J. Role of transforming growth factor-beta in muscle damage and regeneration: focused on eccentric muscle contraction. Journal of exercise rehabilitation. 2017;13(6):621-6; doi: 10.12965/jer.1735072.536

[29] Wang X, Li F, Xie L, Crane J, Zhen G, Mishina Y, et al. Inhibition of overactive TGF-beta attenuates progression of heterotopic ossification in mice. Nat Commun. 2018;9(1):551; doi: 10.1038/s41467-018-02988-5

[30] Walczak BE, Johnson CN, Howe BM. Myositis Ossificans. The Journal of the American Academy of Orthopaedic Surgeons. 2015;23(10):612-22; doi: 10.5435/JAAOS-D-1400269

[31] Martin PT, Golden B, Okerblom J, Camboni M, Chandrasekharan $\mathrm{K}, \mathrm{Xu} \mathrm{R}$, et al. A comparative study of $\mathrm{N}$-glycolylneuraminic acid (Neu5Gc) and cytotoxic T cell (CT) carbohydrate expression in normal and dystrophindeficient dog and human skeletal muscle. PLoS One. 2014;9(2):e88226; doi: 10.1371/journal.pone.0088226

[32] Bassaganas S, Perez-Garay M, Peracaula R. Cell surface sialic acid modulates extracellular matrix adhesion and migration in pancreatic adenocarcinoma cells. Pancreas. 2014;43(1):109-17; doi: 10.1097/MPA.0b013e31829d9090

[33] Varki NM, Varki A. Diversity in cell surface sialic acid presentations: implications for biology and disease. Lab Invest. 2007;87(9):851-7; doi: 10.1038/labinvest.3700656

[34] Baghdadi MB, Castel D, Machado L, Fukada SI, Birk DE, Relaix F, et al. Reciprocal signalling by Notch-Collagen VCALCR retains muscle stem cells in their niche. Nature. 2018;557(7707):714-8; doi: 10.1038/s41586-018-0144-9

[35] Ho HH, Gilbert MT, Nussenzveig DR, Gershengorn MC. Glycosylation is important for binding to human calcitonin receptors. Biochemistry. 1999;38(6):1866-72; doi: 10.1021/bi981195e

[36] Capkovic KL, Stevenson S, Johnson MC, Thelen JJ, Cornelison DD. Neural cell adhesion molecule (NCAM) marks adult myogenic cells committed to differentiation. Exp Cell Res. 2008;314(7):1553-65; doi: 10.1016/j.yexcr.2008.01.021

[37] Suzuki M, Angata K, Nakayama J, Fukuda M. Polysialic acid and mucin type o-glycans on the neural cell adhesion molecule differentially regulate myoblast fusion. J Biol Chem. 2003;278(49):49459-68; doi: 10.1074/jbc.M308316200 